\title{
Bioethics and Disability Rights: Conflicting Values and Perspectives
}

\author{
Ron Amundson • Shari Tresky
}

Received: 17 September 2007 / Accepted: 7 February 2008 /Published online: 14 May 2008

(C) Springer Science + Business Media B.V. 2008

\begin{abstract}
Continuing tensions exist between mainstream bioethics and advocates of the disability rights movement. This paper explores some of the grounds for those tensions as exemplified in From Chance to Choice: Genetics and Justice by Allen Buchanan and coauthors, a book by four prominent bioethicists that is critical of the disability rights movement. One set of factors involves the nature of disability and impairment. A second set involves presumptions regarding social values, including the importance of intelligence in relation to other human characteristics, competition as the basis of social organization, and the nature of the parent-child relationship. The authors' disapproval of certain aspects of the disability rights movement can be seen to be associated with particular positions regarding these factors. Although the authors intend to use a method of 'broad reflective equilibrium,' we argue that their idiosyncratic commitment to particular concepts of disability and particular social values produces a narrowing of the moral significance of their conclusions regarding disability rights.
\end{abstract}

R. Amundson $(\bowtie)$

University of Hawaii at Hilo,

200 West Kawili St.,

Hilo, HI 96720, USA

e-mail: ronald@hawaii.edu

S. Tresky

Hilo, HI, USA
Keywords Disability rights - From chance to choice Reflective equilibrium · Impairment · Eugenics

\section{Introduction}

This paper explores the grounds for the ongoing tensions between mainstream bioethics and advocates of the disability rights movement. In their early days the two movements shared concerns: they were skeptical about the power and paternalism of the medical establishment, and strongly supported the autonomy of the patient [1]. Since the 1970s the field of bioethics has grown tremendously, primarily because of the Human Genome Project and the program called "Ethical, Legal, and Social Issues" (ELSI) which is a part of it. The emerging genetic technologies have led many bioethicists to discuss the nature of disability and the lives of people with impairments, in order to justify particular recommendations regarding genetic policy. Disability rights advocates gradually became aware of the bioethicists' writings, and found much of it objectionable. Many felt that bioethicists were mistaken about the causes of disability, about proper policies regarding prevention of disability, and indeed the very nature of life for a person who has an impairment [for overviews see 2-5].

This paper will critically examine a book that has become an influential source of these disagreements between bioethicists and disability rights advocates: 
From Chance to Choice: Genetics and Justice. This book, coauthored by four prominent bioethicists, represents what is probably the dominant strand of bioethical thought on disability and genetics [6]. The research was funded by the ELSI program, and was extremely well received within the bioethics community. Ethical problems that arise from modern biomedical science are analyzed in terms of the justice theory of John Rawls, using a method called reflective equilibrium. This method involves a careful attempt to work out any inconsistencies between apparentlyacceptable moral principles (none of which is absolutely basic) and intuitive judgments about individual moral cases (none of which is immune from revision). The topics under consideration are supposed to apply to an entire diverse society, and so the authors claim to engage in broad reflective equilibrium - they consider intuitions and principles that potentially conflict with their own. In line with this ambition, many sections of the work are dedicated to showing that a particular genetic or medical policy would be acceptable to people with a wide range of ethical beliefs, not just to those whose values match the authors. The book directly addresses certain critiques of medical and genetic practices that come from disability rights advocates. The main focus of these critiques is the practice of offering prenatal tests to detect genetic markers associated with impairments and the subsequent offer of selective abortion of fetuses with those markers, practices that are almost universally endorsed by the biomedical community [3]. Although the authors' primary concern is to defend these practices against the critiques, they address the arguments of disability rights advocates in a number of other contexts throughout the book. This is unusual among mainstream bioethics texts.

One feature of From Chance to Choice (henceforth FCC) should make it attractive to disability rights (henceforth DR) advocates. A section in Chapter 7 entitled "Distinguishing Disabilities from Impairments" is a brief but articulate account of the social construction of disability, even using the vocabulary that has become standard within the British wing of the movement (284-7; unless otherwise specified all page numbers refer to [6]). Under this model, impairments are biomedical conditions, and disabilities are the disadvantages that people with impairments experience in environments which contain barriers to their participation. "Whether an impairment...results in a disability depends on the social environment of the individual" (287). Despite this seeming understanding of the social construction of disability, the overall stance of the book with respect to DR is persistently negative. Chapter 7, which contains the "Distinguishing Disabilities" section, is actually devoted to challenging the DR critiques of modern genetics. The challenge goes well beyond the DR critiques of genetic policy. The authors argue for a strict distinction in moral legitimacy between the DR movement and other civil rights movements. Discrimination on the grounds of "race," ethnicity, sex, religion, and sexual preference is said to be categorically unjust. Members of dominant groups have no morally legitimate interest in discriminating against members of these groups "because no one can have a morally legitimate interest in preserving unjust arrangements" (283). However, the same criterion does not apply to discrimination on the grounds of impairment. The authors claim that even though people with impairments have a legitimate interest in integration, the nondisabled majority has an equally legitimate interest in maintaining a social arrangement that excludes people with impairments. This special anti-disability-rights interest is called the "maximizing interest." Integration of people with impairments would (allegedly) conflict with the interest of the nondisabled majority in maintaining (maximizing) a highly efficient and competitive economic system. Justice requires a balance between these two competing morally legitimate interests (292). On this analysis, DR is a second-class civil rights movement, with less legitimacy than other such movements. These arguments do not merely reject the DR critiques of modern genetic policiesthey are a direct challenge to the civil rights status of the movement.

We have analyzed the anti-DR arguments of FCC elsewhere, and will not do so here [7]. Instead we will present some unacknowledged values and interests that we believe underlie the authors' skeptical attitude towards the DR movement. These factors come in two general categories. Part I examines the first category of factors, the authors' conception of the nature of impairment, disability, and the DR movement. Part II examines the second category, a set of presupposed social values that play a role in shaping the authors' conclusions. Although the authors intend 
their arguments to be acceptable to people with a broad range of social and moral values, we believe that the values expressed in the book are in fact more personal and idiosyncratic than the authors recognize. These include opinions about the immense importance of intelligence in comparison to other human attributes, the nature of social relations, the probability of near-limitless medical advances, the nature of the parent-child relationship, and the nature of impairment and the DR movement.

\section{Part I: Impairment, Disability and the DR Movement}

\section{Comparing Civil Rights Movements}

We will begin by documenting the authors' treatment of the DR movement as compared to other civil rights movements. The simplest method of documentation is to locate the numerous places in which the authors list categories of civil rights movements, and compare the treatment of disability to other movements in their discussions of those lists. Of the seven distinct discussions that deal with civil rights movements, disability is completely absent from four (pages 16 , $172,188,220-1)$. The lists that exclude disability all include race/ethnicity and sex/gender, and some of them add class and sexual orientation. Disability is included in two other lists. One of these lists distinguishes between the earlier and the later categories of civil rights protection (race was early, sexual orientation was later: 126). The other reports the classes that had been oppressed under the eugenics movement: race, class and disability (110). The seventh example compares disability to race and homosexuality. This is the argument sketched in the Introduction, which concludes that disability rights has less moral legitimacy than other movements (283).

The two lists that include disability (without challenging the DR movement) are mere historical reports, with no statements of moral approval, while the four lists that exclude disability occur in contexts in which the authors express strong moral agreement with the legitimacy of those civil rights. Other civil rights movements are offered as established and unquestioned moral insights. These are included within the authors' reflective equilibrium without challenge. In contrast, they regard the DR movement as a problem to be dealt with and refuted. Though they commend the effort to change "negative attitudes" towards impairment, they criticize almost every specific DR argument that they discuss, and they relegate the justice claims of the movement to a lower status than other civil rights movements.

\section{Unfamiliarity with the DR Movement}

The authors of FCC offer very little documentation regarding DR positions (only two minor citations of DR writings), and mischaracterize certain central DR arguments. We discuss these shortcomings in detail elsewhere [7]. The deficit of documentation together with the frequency of mischaracterizations indicates a more comprehensive lack of awareness about DR concepts and sensibilities. Apart from the section "Distinguishing Disabilities from Impairments," they show very little familiarity with the DR movement. They are certainly unaware of what one might call the collective consciousness of the DR movement: the sense of solidarity and mutual regard that people in the movement have for other people who are, and have been in the past, disabled by society. They also lack an up-to-date understanding of and sensibility about certain terms and myths relating to disability. This section will offer examples of this lack of awareness.

Like most advocates of the Human Genome Project, the authors are aware of public concerns about connections between modern genetics and historical eugenics of the period up to and including World War II. They want to allay those fears. The best documented section of the book is Chapter 2, which is described as an 'ethical autopsy of eugenics.' The authors are also aware of the criticisms that the disability rights movement has made of modern genetic policies; Chapter 7 is devoted to considering and eventually refuting these criticisms. These two topics-Nazi eugenics and modern disability rights critiques of genetics - intersect in an important way.

DR advocates are concerned with historical eugenics for one simple reason: Eugenic policies were almost exclusively targeted at people who had, or were perceived to have, impairments. People were sterilized, segregated, and killed because they had impairments. The central focus of the DR concern with eugenics is the Nazi Aktion T-4 program, in 
which up to 100,000 children and adults with impairments of various sorts were murdered ('euthanised') by the Nazi regime. This happened under medical care, and prior to the programs of mass murder in concentration camps. The very equipment that was used in the camps - shower heads fitted with poison gas jets and portable crematoria-was used first in asylums, to murder people with impairments $[8,9]$. It is impossible to describe the depth of disability rights advocates' fears about eugenics without recognizing that the Nazi Holocaust began with disabled people.

In Chapter 2 the authors briefly acknowledge that eugenics targeted people with impairments, but show no recognition that DR advocates have a special interest in this fact. The only acknowledgement of Aktion T-4, the Disability Holocaust, is a reference to "the murder of handicapped "Aryans"” (28). The victims of early eugenics are described as "the unfit", those who were "judged to have substandard genes." Later, in the detailed account of "The Nazi Debacle," there is no mention of disability. "The sterilization and 'euthanasia' programs...were an exercise in negative eugenics designed to improve the native German stock from its degenerated condition" (37). In point of fact, the Nazi exercise was precisely the murder of tens of thousands of people, children and adults, with mental and physical impairments. There is no mention of the impact of the historical atrocity on current DR consciousness.

What can we make of the reference to "handicapped 'Aryans"'? The authors place skeptical quotes around the racial term 'Aryans' but not around the dehumanizing, eugenic and equally unscientific term 'unfit.' From the perspective of many DR advocates, the Nazis were not murdering 'Aryans' but were murdering people who had (or were perceived to have) impairments. Many DR activists identify with those victims in the very same way that many modern Jews identify with the Jewish victims of the Holocaust. The fact that they were 'Aryans' is absolutely irrelevant (as is the fact that many Jewish victims were ethnic Germans and citizens of Germany). The Nazi Holocaust began with disabled people. Authors who underestimate the importance of this fact to DR advocates are not likely to appreciate their eugenic concerns.

The book contains several expressions that also conflict with a DR consciousness. One is the casual use of the term 'idiot savant' (193 no. 29). Even though the term is placed within single quotation marks, it is used as the label for a type of cognitive disability. The authors do not intend to insult, but they appear to be unaware that the old medical term 'idiot' is now regarded as harshly derogatory. Other examples sound condescending rather than derogatory; here is an example. Many bioethicists consider the quality of life of people with impairments to be extremely low, and they are aware that DR advocates disagree. The authors of FCC try to acknowledge the possibility of a high-but-disabled quality of life by referring to "the rich inner life of the blind" (168). Why should blind people be restricted to an "inner" life? Such a reference is condescending in the same way as the old legends about the athletic or rhythmic prowess of "racial" minorities.

One final example of the lack of perspective towards a DR consciousness is the analogy by which the FCC authors introduce the 'maximizing interest', the core of their criticism of the legitimacy of the DR movement. The analogy involves decisions about a card game to be played by a group of people. If all the players are adult, they might choose to play contract bridge. But if the group includes five-year-old children, the children would be unable to play bridge. To include everyone in the card game, a much simpler game such as Go Fish must be chosen. This would ruin things for the adults, who have an interest in playing a game that is demanding to them, a game like bridge. Integrating children into the game would violate this interest. The authors now reveal their conception of disability. They claim that the conflict of interests between adults and children in the card game example parallels the conflict of interests between nondisabled and disabled people in modern society (288 ff.). The adults' interest in playing a demanding card game is similar (the authors claim) to the interest that nondisabled people in the real world have in excluding disabled people from the activities of everyday life. This is 'the maximizing interest'. If disabled people were integrated into contemporary society, social activities would have to be simplified to the extent that everything a nondisabled person could do, a disabled person could also do. Such a world would violate the maximizing interest. "As the example of the very young children attempting to play contract bridge shows, participation by 'disabled' individuals can cause 'discoordination' and reduce the benefits that 
the 'abled' might otherwise reap from complex forms of cooperation" (290).

As indicated previously, this paper will not challenge the FCC critique of the DR movement (but see [7]). The falsity of their assumptions regarding the integration of people with impairments is clear to anyone experienced in DR. We wish only to call the readers' attention to the nature of this central analogy. Nondisabled people are likened to adults, and disabled people to children. It is difficult to imagine a more patronizing analogy. The ostensive conclusion relies on the fact that adults are more technically competent than children. But the analogy carries a second message. Children do not make their own decisions; they are incompetent to do so. Adults decide for them. This is another painful point in the history of disability. Decisions about the treatment of people with impairments have very often been withheld from those people, and made by authorities who were nondisabled $[10,11]$. For good reason, the favorite slogan of many DR advocates is "Nothing about us without us." When the authors of FCC liken disabled people to children, they reveal their shallow understanding of the DR movement.

\section{Semantic Indications of Attitudes}

The authors' choices of words to describe certain phenomena reveal their prejudices about them. We will here consider certain key words used to describe (1) the removal of environmental barriers, and (2) the subjective nature of impairments.

Barrier removal as special and as a burden The word 'special' has long been recognized by the DR community as a way of stigmatizing accommodations, and retaining a flavor of segregation for facilities that are designed to integrate people with different functional abilities [12]. The authors' frequent use of this term conveys a belief in the difficulty and expense of environmental accommodation $(244,261,292,301)$. The best accommodations, like curb ramps on sidewalks, are permanent features of the environment that can be used by anyone. Nevertheless, the label "special" can make it seem as if the curb ramp was installed at great expense, and only for the convenience of one person with a wheelchair. A perfect example of this use occurs in a list of factors that the authors claim parents should consider before deciding to bear a child with an impairment:

...the extent of society's obligation and efforts to make special accommodations to eliminate or ameliorate the disability, and their willingness to assume the burdens of raising a child with the disability in question (301, emphasis added).

Besides the stigmatizing term 'special,' this passage also exhibits the key word 'burden.' Elsewhere the authors state that "in many cases" environmental accommodations are not "unduly burdensome to others" (320). They actually present this statement as if it expressed support for DR. But it does not. In addition to the stigmatizing term burdensome, the statement clearly implies that except for those "many cases," environmental accommodations truly are undue burdens for people who do not have impairments. It is doubtful that they would think of saying such things about actions that helped to integrate women or minorities into mainstream life.

The authors' characterization of the experience of impairment has two problematic themes, loss and suffering.

Impairment as loss The theme of loss includes such concepts as deficit, which is said to diminish the life plans and limit the opportunities of those who have impairments (e.g. 168, 332). No discussion is included about people who did not lose their sight, or hearing, or their ability to walk, but were born without it. It is well documented that such people do not experience a loss or diminishment. Nor is there any mention of people who experienced a loss or diminishment when they first became impaired, but who later adapted to the impairment and no longer experience it as loss or limitation. This is not a mere semantic oversight. It implies a mistaken understanding of the nature of impairment. Research in social psychology has shown that very many people falsely assume that the experience of living with an impairment is the same as the experience of acquiring that impairment [13]. This just isn't true. Acquiring an impairment is experienced as a loss; living with an impairment is not.

Impairment as suffering No direct connection exists between impairment and suffering. Even though some medical conditions cause both suffering and function- 
al limitation, functional limitation itself does not cause suffering. Nevertheless, the authors of FCC assume a link between impairment and suffering as if it were a definitional truth. One long discussion concerns the decision to have a child who will have moderate intellectual impairments (244-257). Such impairments do not typically cause suffering in any direct sense. But the authors' use of the word suffering escalates throughout the discussion of the case. Eventually, still discussing this same case, the term 'suffering' occurs fifteen times on a single page!

The authors' choice of language in describing advances in medical treatment reveals another deep bias. Medical research is described as following the Western tradition's "zeal for progress" and the "noble" quest of "the pursuit for the greater good of humanity as a whole" (263). No such praise is given to advances in accessibility, even though the authors admit that these can remove disabilities (i.e. sociallymediated disadvantages) too. Environmental barrier removal is special accommodation, and a burden on the nondisabled majority; impairments are losses that cause suffering that can best be addressed by medical or genetic solutions. Such terms are key words for impairment, and their use seems almost involuntary. Medical treatments, on the other hand, are said to be aimed at the good of society as a whole, not as "special" benefits for the individuals who need them. The costs of socially funded medical treatment and socially funded research for diseases that affect only small portions of the population can be seen as equally "burdensome" to people who do not have those diseases. But these authors never describe them in this way. Indeed, a system of universal medical care is one of the authors' primary goals. Universal accessibility to people with impairments is a very different story from universal health care for people with illnesses - at best it is 'special,' at worst it is an undue burden.

The authors characterize one set of human phenomena as 'burdens,' 'suffering,' and 'special.' They characterize another set as 'progress,' 'noble,' and 'the common good.' The first set of phenomena includes impairment and accommodation; the second set includes illness and its treatments. The bivalent distinction between the two kinds of phenomena is not congruent with the points that were agreed to in "Distinguishing Disabilities from Impairments." Their choice of language reveals a great respect for medical research, but a disregard for the goals of the DR movement. We again revisit the "Distinguishing Disabilities" section not to illustrate the book's inconsistency (which may be partly due to the fact of multiple authors) but to contrast a genuinely DR consciousness with the predominant opinions that are expressed in FCC. If the section had not been written, we would have expressed the contrasting DR perspective ourselves.

\section{Part II: Idiosyncratic Assumptions of Social Values}

\section{Professional Bias}

In the first chapter of FCC, the authors discuss the dangers of what they call "gene-mania." They discuss the fact that genetics has sometimes been used to "conveniently blind ourselves to the uncomfortable possibility that many of our most serious problems result from our social practices and institutions" (24). They deny that they are genetic determinists, they assure the reader that they will not lose sight of the importance of social causes for disadvantage, and they claim that their analysis will not be used to excuse unjust social practices (26). Unfortunately, this promise is not fulfilled with respect to disability. Except in "Distinguishing Disabilities from Impairments," the disadvantages of impairment are most often directly attributed to medical conditions (impairments), with little recognition of the social causes of disadvantage other than general references to "negative attitudes towards people with disabilities" and so forth $(15,279)$.

The authors stipulate early in the book that they will purposefully over-state the powers of genetic medicine in order to create a context for exploring the ethical issues it creates. This is a justifiable strategy as long as the authors keep firmly in mind that it is only a rhetorical technique. But as the book goes on, the emerging medical utopia sounds more and more like an empirical truth. This utopian view of medicine may stem from the authors' position within the medical community, but their bias seems to prevent them from fully appreciating the role of environmental barriers in creating social disadvantage.

Let us consider one example of the effects of the authors' medical utopianism, their analysis of the 
crucial importance of universal health care. This is a major conclusion of the book. Universal healthcare is said to be a requirement for justice because people with illnesses and/or impairments are socially disadvantaged. Health care can prevent or cure illness and impairment. The authors adopt the popular view that there is a strict biomedical distinction between normal and abnormal conditions. (The objectivity of the normal/abnormal distinction has been challenged by some DR authors [14-16].) The authors frequently state that the ultimate goal of medicine is to make ill and disabled people into "normal competitors" (122, 127 , 148, etc.). Justice is served by equalizing opportunity among individuals, or (in the authors' competitive metaphor) by leveling the playing field. This is achieved by making as many people as possible comply with biological normality.

So far, so good. We agree with the need for universal health care and equality of opportunity. However, people with chronic illnesses and incurable impairments are left out of the equation. Because these people cannot be "normalized," they appear to count as medical failures by the authors' normalitybased definition of the goals of medicine. More importantly, the playing field is not leveled for them like it is for patients who can achieve the ideal of normality. The DR movement offers a different and equally important way to level the playing field, which even works for people with permanent impairments: remove the environmental barriers that segregate people with impairments. The authors acknowledge that integration by barrier removal is a legitimate interest of people with impairments, but it is said to be opposed by the maximizing interest (288). Whose interest is the maximizing interest? It belongs to the "normal competitors," those whose playing field was leveled by genetics and medicine. These "normal competitors" are said to have a legitimate interest in maintaining a competitively productive society, and this may require segregating people with permanent impairments.

So the authors regard the goal of normalizing the workforce (by medical means) to be higher than the goal of integrating people with permanent impairments (by environmental means). The first goal is categorical, directly required by justice, while the second goal is contingent on balancing the interests of the "normal competitors" against the interests of people with impairments. Other theorists, more economically laissez-faire than the FCC authors, might treat medical normalization in the same way that FCC treats environmental accommodation. Such a view would oppose universal health care in the same way that FCC opposes universal environmental accommodation for impairments. It would insist that normalization must be weighed against the 'maximizing interests' of people who are wealthy enough to purchase their own private health insurance, or are fully healthy and do not require normalizing medical services. Our authors disagree. For them, medical normalization is a simple, categorical goal of a just society. But environmental accommodation for citizens that cannot be made 'normal' is a matter of complex negotiations with 'normal competitors' who are assumed to have an opposing interest. Here we see how the authors' views on the purpose of genetics and medicine affect social justice for the minority that cannot be normalized. Recall that they had explicitly stated that they would not use genetics to excuse unjust social practices (26). We submit that the concept of "normal competitors," with their special interest in excluding people with impairments, provides precisely that excuse.

\section{The Best Child}

Although the authors strive to avoid genetic determinism, they do not succeed. And, in fact, their view implies a broader form of biological determinism. This is particularly evident in the discussion of the best child in Chapter 5. The authors acknowledge that changes in either genes or environment can bring about similar effects on an organism (160). This acknowledgement represents the authors' rejection of genetic determinism (because genes are not privileged over environmental causes). If genetic and environmental causes were genuinely given similar treatment, genetic determinism would indeed be avoided. But the subsequent discussion shows otherwise. Genetic interventions are said to be able to "produce the best offspring" and "make the best child" $(156,159,161$, 162). This vocabulary of producing and making is used only to describe the effects of genetic intervention, never to describe the effects of environmental modification. Instead, environmental influences are described as "best for the child" (157-9, emphasis added). A child said to be 'produced' or 'made' by genetic manipulations that occur before birth. Envi- 
ronmental influences are said to be best for the child, when the child already has an identity that can be benefited. The idea that genetic interventions actually produce the best child implies that genetic effects are the child in a sense that environmental effects are not. This view itself is not idiosyncratic. In modern times, many people assume that genetic identity (or genome identity) contributes to personal identity in a way that environmental influences do not. Nevertheless, our authors make full use of this privileging of genetic over environmental causes even while they decry genetic determinism.

The theme of Chapter 5 was quite striking to us. The chapter begins by stating as an obvious truism the claim that parents want the best child: a section is entitled "What Could be More Natural than Parents Seeking the Best?" (156). The authors acknowledge that not all parents actually have such a competitive breeding goal, and they recognize that such a proposal will "raise anti-eugenic hackles." Still, they seek to encourage this perspective in their readers. No mention is made of the widely-held view that the family is a refuge from the competitive marketplace, and parents are expected to love their children regardless of their intelligence, beauty, or athletic prowess. That perhaps-naïve doctrine-that parental love is unconditional, or at least not eugenically calculating - is, we believe, more widely accepted within our society than the competitive goal of producing the best child. We believe that the authors' advocacy of eugenic competitiveness among parents truly is idiosyncratic; it sets them apart from the values of most people in our society. If we are correct, this is a clear example in which the reflective equilibrium of the authors is narrower than the society that they claim to represent.

The authors say that their plea for "the best child" should be understood from the standpoint of the child's own interests in having a good life, without regard for parents and society (164). From this standpoint it seems that "the best child" is the child that will have the best life, the happiest life. However, the genetic techniques that they advocate simply do not support this assertion. High among these techniques are screening procedures such as amniocentesis and pre-implantation screening. These identify fetuses and zygotes with potential impairments before they are implanted or born, so that their births can be prevented. In this case "producing the best child" does not reflect the standpoint of the child's own good at all (at least if we conceive "the child" to refer to "the entity which is receiving the genetic treatment"). Preventing the birth of a zygote or fetus (whose life would be worth living) cannot be seen as in that fetus's interest, as the authors acknowledge (see the following section). The parents, the society, or the child who is "substituted" for the child not born would seem to be the only possible beneficiaries of selection. This brings us to the topic of 'wrongful disability.'

\section{Wrongful Disability}

What makes the best child? First and foremost, she or he must not be impaired. The unique badness of impairment becomes evident in a long discussion in which the authors consider, and defend, the notion of 'wrongful disability.' The claim of wrongful disability was originally made on behalf of children with genetic impairments whose mothers' gynecologists were said to have failed to warn them of the impairment so that an abortion could have been performed. The meaning of wrongful disability has expanded to include the claim that is morally wrong to have a child with an impairment when it is possible to have a different, non-impaired child instead. The authors support this claim. Wrongful disability would apply to parents who choose not to abort a child with a diagnosed impairment (when they could undergo a subsequent pregnancy). It would apply to parents who, in choosing among preimplanted zygotes, choose one with a diagnosed impairment over one with no diagnosed impairment. It would apply to parents who failed to perform preimplantation or prenatal diagnosis when they could have, and subsequently had a child with an impairment.

The authors make certain provisos regarding wrongful disability. First, they make allowances for parents who believe that fetuses have a right to life, on the general grounds of reproductive freedom. Second, they stipulate that wrongful disability cases only involve people whose lives are worth living even though they have impairments (when the choice involves an impairment that is so bad that such a life is not worth living, the case would be classified as "wrongful life" rather than "wrongful disability"). This stipulation defends the authors against the frequent charge on the part of DR activists that 
bioethicists believe that disabled lives are not worth living. The authors believe that, under the conditions they discuss, disabled lives that are worth living, should, nevertheless, be prevented from being lived.

Defense of the concept of wrongful disability has run into problems both from the courts and from some philosophers. Wrongful disability is said to be an incoherent concept. The problem is that no actual person is harmed (wronged) by the birth of a child with an impairment. The impairment could only have been avoided by having a different child than the existing child (that is, the child with the impairment). So the existing child with the impairment is not wronged-her or his life is worth living, and another choice would have taken that life away. And the nonimpaired "substitute" child wasn't wronged, because she or he does not exist in the first place! This is called the 'non-identity problem.' The authors deal with this problem by developing a line of thought called 'avoidability by substitution'. The idea is that parents who know that they are likely to bear a child with an impairment (because of prenatal diagnosis for example) are morally obligated to end that pregnancy and attempt to become pregnant with a non-impaired fetus instead. The "instead" is a crucial part of the argument. The argument simply does not work unless different fetuses are considered to be substitutes for one another. If the fetus with the diagnosis is aborted without replacement, then a worthwhile life has been removed from the world. It is not morally wrong for a couple to bring to term a fetus with an impairment if they would be unable to later conceive another fetus without an impairment. But it is morally wrong for them to do that very same thing if it were possible for them to later give birth to a child without an impairment.

The so-called non-identity problem was discovered by Derek Parfit [17]. Parfit is not an ethicist. He is a specialist in the metaphysical problem of personal identity, one of the most perplexing and seemingly irresolvable of metaphysical questions. Parfit created a major new problem for ethical theorists (like the authors of FCC) by pointing out that many human decisions in the modern world affect not only the welfare of future people, but also their very identity. In the simplest case, a woman's choice to use or refrain from using birth control during a given menstrual cycle may result in different children being born. This follows from the assumption (mentioned above) that genetic identity largely constitutes personal identity, together with the fact that a given ovum (or sperm, for that matter) only has the chance to produce a zygote during a given menstrual cycle. Following Parfit, ethicists struggled with the problem of fitting person-changing decisions into the traditional theories of ethics. Parfit and those who followed him were able to devise a satisfactory ethical theory only under one constrained condition. The consensus theory applied only to sets of options under which the same number of (future) people existed under each option. No consensus could be found for pairs of decisions that changed the number of people that existed in the world. The consensus rule states this: When choosing between options in which the same number of future people exist, the morally right action is the one in which the people that turn out to exist have the highest quality of life (whatever their identity might be). (For choosing between options that involve different numbers of future people, no consensus theory could be reached. The reasons for this are densely technical and beyond the scope of the present paper.) The authors of FCC simply apply that consensus rule to the situation of a mother choosing whether or not to bear a certain child. The result is that a woman who knowingly bears a child with an impairment, when she could have borne a child with no known impairment, has done something wrong. This is why "instead" is a crucial part of FCC's discussion of wrongful disability. If different numbers of future people are involved in the future options (for example, if a woman pregnant with a fetus that has an impairment cannot become pregnant again if she terminates the current pregnancy), then the consensus rule simply doesn't apply because the numbers of people are not the same in every option. The consensus rule is what implies the substitutability of children.

We will not wrestle with the formidable metaphysics of the non-identity problem in this paper. Instead we wish to discuss the consequence of that rule, the concept of the substitutability of children. We submit that the notion of the substitutability of one child for another is contrary to most people's concepts of family life. Children are not ordinarily thought of as substitutes for one another, as they must be for the "avoidability by substitution" doctrine to work. One context in which children have actually been seen as substitutes for one another is under recent laws in 
China according to which family reproduction is limited to one child. It is reported that female fetuses are frequently aborted in China in order to "substitute" males as the legally mandated one-child. This practice - both the legal limitation and the resulting abortions - is seen as reprehensible by most people within our society (and probably by the authors as well). However, the authors adopt a policy towards fetuses with impairments that places them in a very similar position to female fetuses under the Chinese one-child law. This, we propose, is contrary to broad reflective equilibrium. However well the principle of avoidability by substitution avoids the non-identity problem (and defends the authors' intuitions regarding the wrongness of bearing children with impairments), it carries with it an objectionable view of the nature of the family.

We will note one additional peculiarity of the authors' solution to the non-identity problem. When a fetus or zygote is kept from being born, for whose sake was that act done? As the non-identity problem implies, it cannot be for the sake of the terminated fetus, because that fetus would have had a life worth living if it hadn't been terminated. In seeking to avoid stating that the act must have been done for the sake of the parents or society, the authors provide a resolution that requires considerable logical contortion. They propose that the termination of a fetus or zygote with an impairment is done "for the sake of less overall suffering and limited opportunity" (251). Recall that suffering and limitation of opportunity were key words for impairment, the suitability of which we have already challenged. The discussion of wrongful disability is one more context in which "limited opportunity" is attributed directly to an impairment, with no consideration of how social circumstances contribute to that limitation, despite the authors' pledge to consider social as well as biological causes of disadvantage.

We end this discussion with a poignant illustration of the authors' view on wrongful disability. In discussing the possibility that parents might sometimes make the wrong choices in child rearing, the authors of FCC point out that parental decisions might be affected by "racism, classism, or sexism" (172). Why do they not include ableism (prejudice against people with impairments) in this list? There is a straightforward answer to this question. It is because ableism is precisely the grounds on which the authors believe that parents should make such decisions as abortion in cases of prenatal diagnosis.

Overarching Social Values: Intelligence

Within Individuals and Competition Between Them

Throughout the book, intelligence is described as the most important human trait, and competition is alleged to be the foundation of social organization. The authors elevate intelligence to the status of a virtue - an unquestioned universal good. They openly agree with historical eugenicists on this issue: "[I]n the main the eugenicists focused on a very short list of traits about which there is little controversy...intelligence dominated the list...we would not fault the eugenicists for believing that raising the level of intellectual ability in the human population would result in human betterment" (48-9). No other human trait comes close to intelligence in the importance placed on it by the authors. The bias is illustrated in the way the authors discuss conditions that reduce intelligence. The false assumption discussed previously, that moderate intellectual impairment causes suffering, is one case in point. The truth is that many people with intellectual impairments are extremely cheerful, and many highly intelligent people are unhappy. There is no established positive link between intelligence and happiness [18-20].

Some early eugenicists advocated selection for empathy, altruism and cooperation. The authors disagree. Their criticisms make good sense in one way: such traits are double-edged; they can lead to either positive or negative outcomes. They offer a striking thought-experiment to illustrate this point. The character Cynthia has an enhanced "ability to modulate emotional response" - she is good at empathizing with people and reading their emotions. Cynthia sounds like a wonderful person, until you learn that she is a criminal who swindles people by pretending to be friendly and concerned (180). The point is important. Interpersonal skills can be used for good or bad. Surely the double-edge point applies equally to intelligence: a brilliant con artist causes more harm than an unintelligent one. But the authors scarcely acknowledge the double-edged nature of intelligence, agreeing with the eugenicists on its unique value.

The authors offer a second thought-experiment that considers a national policy of selection for altruistic or 
cooperative traits (173-4). They recognize a legitimate governmental purpose for such selection (a cooperative populace), but worry that it would conflict with parental desires. The authors consider reproductive freedom (and therefore parental rights) to take precedence over such governmental interests. We were struck by one feature of this discussion: the authors never consider that parents might actually prefer an altruistic, kind, or cooperative child to a highly intelligent one. The thought experiment reflects not only their doctrine that competition is the core of social relations (even if governments might disagree), but also their expectation that parents agree with them.

As a matter of documented fact, high intelligence and competition are not universal values of our multicultural society. Many subgroups make abortion decisions on grounds quite different from the authors' assumptions. People in some Latino subcultures appear to be almost uninterested in diagnoses of intellectual impairments in fetuses that are being considered for abortion, expressing more concern for the "normal" appearance of the child [21: 225-6]. A child with low intelligence can always get help from others, but a child with abnormal appearance (e.g. being unable to walk) might be socially ostracized. African American families have an overall abortion rate similar to white Americans. However their abortion rate for a prenatally diagnosed impairment in a wanted pregnancy is far lower than that of white families [22: 550]. We should remember that the authors are positioned at the very top of a primarily white profession that is founded on competitive intellectual ability. (Remember the grim academic slogan "publish or perish.") It would be surprising if they did not value intelligence and competition in their children. Parents who are athletic often value athleticism in their offspring, parents who are professional mechanics value mechanical aptitude in theirs. However, these valuations are not shared by everyone in our society.

For many of us, the "normal competitors" (competitive high achievers) are not the kind of people we like to work with, let alone live with. In the workplace, as well as in other spheres of life, many people value a kind and cooperative spirit far more than competitive intelligence. Even in circumstances which involve competition, its value is combined with that of loyalty to the family, to the team, to the corporation, or to the nation. One review of FCC shows how the authors' reflective equilibrium excludes an alternative feminist perspective. One important aspect of the feminist viewpoint is that it challenges "the normative representation of persons as competitors," which is an "accurate picture of only some people's lives, some of the time." The reviewers go on to say

...surely we are entitled to an argument as to why this particular feature of persons [referring to the feature of competition] is more relevant to justice than, say, people's dependency on one another, their vulnerability to catastrophic hardship, or their ability to cooperate. A reverence for the historical resonances of justice theories [referring to FCC's commitment to Rawlsian theory] is not adequate as a response [23: 71].

It is our belief that several of the authors' social values are idiosyncratic, and undeserving of the privileged position they hold within the authors' reflective equilibrium. These include intelligence as a virtue, intellectual impairment as a form of suffering, and competition as the fundamental basis of social organization.

\section{Cooperative Framework or Dominant Culture?}

The authors' challenge to the civil rights status of DR is based on the assertion that the nondisabled majority has a morally legitimate interest in maximizing the challenge and productivity of a competitive economic system. They claim that the basic organization of our society (what they somewhat ironically call the "dominant cooperative framework") is highly competitive (259). This is why they so often discuss "normal competitors" rather than ordinary people. The maximizing interest belongs to the normal competitors-people with no impairments, those who have access to the level playing field. This interest is opposed to the DR interest in social integration, which would allegedly degrade the dominant framework. Justice could only be served by weighing these two interests against one another. Is this conflict of interest real?

The fact is that human beings have many other interests that they want to maximize in addition to or instead of the interest in competitive productivity: family life and creative endeavors, to name two. The 
most productive economic activity may not result in the most fulfilling family relationships, and the most enriching creative endeavors may conflict with both economic productivity and a rewarding home life. Individuals vary in the importance they place on each of these, but values are placed on them all- not only on the competitive goal. The authors have set up a false dichotomy between maximum competitive productivity and social integration. This artificial division makes it seem as if unequivocal social integration for people with impairments would be unjust because it violated a valid interest held by others-maximal productivity. Human lives include so many possible goals and sources of enrichment that it makes little sense to isolate people with impairments, and set them up in a contest with nondisabled members of society. For the authors, competition is such a fundamental value that preserving this value becomes the basis for just social policy. However, this extremely high valuation of competition is not shared by everyone. Moreover, the interest in integration benefits everyone- not just those with disabilities.

Dominant voices in the culture are able to articulate what they perceive as the interests of an entire society, even when they are in the minority. It is important to remember that the dominant cooperative framework is a product of those dominant voices. The authors of FCC are prominent biomedical ethicists, and have a much greater influence on social policy than the average person. But average people would benefit from changes in the cooperative framework that may make it less starkly competitive and more inclusive. For example, a society that put a greater value on family life than economic productivity might institute social policies that are more accommodating toward people with impairments, but would also benefit many other people who placed a high value on family life. The conflict of interest is not between people with impairments and people without impairments. It is a conflict between people with different social values - some of whom currently dominate the societal discourse. People with impairments-like everyone else-may try to promote social changes that would make the cooperative framework more inclusive and conducive to their interests. It does not follow that their interests are in conflict with everyone else in society, as the authors depict the situation.
Conclusion: Whose Utopia?

The basic ideology of DR is that people with impairments are entitled to the same civil rights protections enjoyed by other groups in society. Impairments must no longer be regarded as unnatural, but rather as an ordinary fact of life. An architect who is committed to universal design for accessibility comments: "Variation in ability is not special but ordinary and affects most of us for some part of our lives. It makes sense now to design products, environments, and communications to work seamlessly for the widest possible spectrum of users" [24].

The DR utopia is a world without barriers. The FCC utopia is a world composed entirely of 'normal' people, so barriers won't matter. In discussing their argument for universal health care, the authors argue that the DR demand for accessibility will eventually be moot: "At present, however, biomedicine's powers of prevention are very limited. The requirement that workplaces be modified to accommodate persons with disabilities is a reasonable response to the inadequacy of the preventative strategy" (292, emphasis added). According to this utopian perspective, disability rights are only relevant in the short term, but will not be needed in the long term. Our disagreement with this perspective is based on a principle we think of as the Demographic Argument for Disability Rights:

The greatest successes of modern biomedicine are making it possible for people to live longer while they have impairments. The reduction in numbers of people with impairments brought about by total cures and by prenatal selection against impairments is swamped by the increase in the numbers of people who are able to live a long life even while they have impairments. It follows that the proportion of the population which has impairments will be greater in the future than it is now. AND THIS IS A GOOD THING. The alternative is to die younger. Disability rights are perennially important because impairments will always be with us.

Paradoxically, the nondisabled majority will be getting smaller and smaller as biomedicine makes advances. Demands for improvements in accessibility will increase. The DR goal is more relevant now than it has ever been. Anyone concerned with justice, including bioethicists, should support the DR vision 
of a truly integrated world. The old fear that accommodation is burdensome is not only discriminatory against a minority; its implications would make life less rewarding and fulfilling for most people. In a medically advanced society such as ours, discrimination against people with impairments has become obsolete, a relic of the pre-civil rights era.

Acknowledgements This paper has benefited greatly from comments from three anonymous reviewers for the special issue and the special issue editor, Shelley Tremain. RA's research for this paper was supported by National Institutes of Health grants S06-GM08073 and R03-HG3632-01A1.

\section{References}

1. Asch, A. (2001). Disability, bioethics, and human rights. In G. L. Albrecht, K. D. Seelman, \& M. Bury (Eds.), Handbook of disability studies (pp. 297-326). Thousand Oaks, CA: Sage Publications.

2. Wasserman, D., Bickenbach, J., \& Wachbroit, R. (Eds.) (2005). Quality of life and human difference. Cambridge UK: Cambridge University Press.

3. Parens, E., \& Asch, A. (Eds.) (2000). Prenatal testing and disability rights. Georgetown: Georgetown University Press.

4. Boyd, K. M. (2001). Disability. Journal of Medical Ethics, 27, 361-362.

5. Kuczewski, M. G. (2001). Disability: An agenda for bioethics. American Journal of Bioethics, 1, 36-44.

6. Buchanan, A. E., Brock, D. W., Daniels, N., \& Wikler, D. (2000). From chance to choice: Genetics and justice. Cambridge UK: Cambridge University Press.

7. Amundson, R., \& Tresky, S. (2007). On a bioethical challenge to disability rights. Journal of Medicine and Philosophy, 32, 541-561.

8. Lifton, R. J. (1986). The Nazi doctors: Medical killing and the psychology of genocide. New York: Basic Books.

9. Gallagher, H. G. (1990). By trust betrayed: Patients, physicians, and the license to kill in the Third Reich. New York: Henry Holt and Company.
10. Lane, H. (1995). Constructions of deafness. Disability and Society, 10, 171-190.

11. Longmore, P. K., \& Umanski, L. (Eds.) (2001). The new disability history: American perspectives. New York: New York University Press.

12. Woodward, J. R. (1991). Getting rid of 'special'. Disability Rag and Resource, 12, 35.

13. Kahneman, D. (1999). Objective happiness. In D. Kahnemann, E. Diener, \& N. Schwarz (Eds.), Well-being: The foundations of hedonic psychology (pp. 3-25). New York: Russell Sage Foundation.

14. Amundson, R. (2000). Against normal function. Studies in the History and Philosophy of Biological and Biomedical Sciences, 31C, 33-53.

15. Tremain, S. (2001). On the government of disability. Social Theory and Practice, 27, 617-636.

16. Tremain, S. (2006). Reproductive freedom, self-regulation, and the government of impairment in utero. Hypatia, 21, 35-53.

17. Parfit, D. (1984). Reasons and persons. Oxford: Clarendon Press.

18. Lykken, D., \& Tellegen, A. (1996). Happiness is a stochastic phenomenon. Psychological Science, 7, 186189.

19. Hartog, J., \& Oosterbeeck, H. (1998). Health, wealth, and happiness: Why pursue a higher education. Economics of Education Review, 17, 245-256.

20. Alderson, P. (2001). Down's syndrome: Cost, quality and value of life. Social Science \& Medicine, 53, 627638.

21. Rapp, R. (1994). Women's responses to prenatal diagnosis: A sociocultural perpective on diversity. In K. H. Rothenberg \& E. J. Thomson (Eds.), Women and prenatal testing: Facing the challenges of genetic technology (pp. 219-259). Columbus, OH: Ohio State University Press.

22. Wertz, D. C., \& Fletcher, J. C. (1993). Feminist criticism of prenatal diagnosis: A response. Clinics in Obstetrics and Gynecology, 36, 541-567.

23. Nelson, J. L., \& Nelson, H. L. (2001). Book review: From chance to choice: Genetics and justice. American Journal of Bioethics, 1, 70-72.

24. Fletcher, V. (2002). Universal design: Human-centered design for the 21 st century. Design, 102, 4-5. 